\title{
Seeing Double: Decoys and Depictions
}

\author{
CONSTANCE VALE \\ Washington University in St. Louis
}

The images encountered in the contemporary world are multiple; they are animate artifacts, endlessly duplicating and translating so as to shift their constitution over time. At once, they act as intercessors, translating between pictorial, material, and informational realms. Architects have a long history of dealing with the translation of information from images to objects through architectural drawing, making architecture well-suited for staging discourse surrounding images. While contemporary images are radically different from orthography, their potential as translations runs parallel to that of drawing.

Rather than sequester digital imaging, this paper seeks to examine the cross-contaminated worlds of multiple image types. The intention of this investigation is to remain precise in these terms, combining image types not to dilute them, but to look for opportunities for productive hybrids. Understanding how contemporary images can impact architecture and vice versa requires a dualistic analysis of data and picture. As such, we can examine the ways in which physical artifacts confer the aesthetic effects of their data and constraints of their formats on the world of things that are under their spell.

Decoys and depictions - identified in theater sets, photography, dioramas, and other models that lurk at the periphery of the discipline of architecture - form the field of investigation. These objects that become, or attempt to become images present layered image formats that displace the conventional relationship of image frames and screens. These historical model open up possible avenues to consider how architects can take on similar investigations through image translations that inscribe architectural object with their material data. Images as visually comprehensible piles of information that speak to the complicated web of material orders that they chart, geopolitical boundaries they cross, and volume they consume. In this way, we can see images as inherently political enterprises and read their capacity to engage rewriting the material, informational, and volumetric orders.

\section{THE DUPLICITY OF IMAGES}

Contemporary images lead double lives. The world is replete with duplicate images, and these inherently multiple artifacts are constantly being translated, accumulated, stored, uploaded, downloaded, saved, edited, reformatted, printed, and deleted. However, it is not just the proliferated doubles of images that renders them duplicitous; images walk the line between flatness and thickness, between virtuality and physicality. As the atmospheric backdrop of our mediated present, images are information wrapped up in material, and material bound to information.

Architects have long had to contend with translating layers of information between image and object. ${ }^{1}$ Moving between forms and formats, and pictorial and material worlds, translations that are specific to the discipline of architecture require cyclical flattening and inflating, unfolding and reassembling, allowing image and object to impinge on one another. ${ }^{2}$ As such, architecture is particularly apt field of inquiry for discourse surrounding images.

When images are conceived of as exclusively flat, and architecture as only a spatial enterprise, the potentials present in their overlap are constricted, and images become deadening laminations. However, when images are acknowledged to be thick, layered, material constructions, architecture can be enmeshed in those constructions and interrogated through their delaminating, unfolding, and reformatting. Reframed in this way, the rigid corners of architecture begin to loosen and occupy the thicknesses of images.

\section{IMAGING DATA}

In order to interrogate the capacity of images in architecture, it is important to define the term image in contemporary practice. In so doing, it becomes apparent that there is a panoply of ways in which images reveal their contingent digital-material status. These images transgress perceived boundaries as they pass through multiple formats, cross realms of production and presentation, and calibrate to human optics and electronic processing.

Images are duplications in translation, forming composites of the ever compounding information that distorts as it changes formats or travels. ${ }^{3}$ Even their optically calibrated information propagates doubles that resemble, but are inherently distinct from, preceding versions. In this profusion of likenesses, images are never singular. They are animated artifacts, both inputs and outputs, unstably shifting their constitution and forming their histories across distance and time. Furthermore, from screen to print, images are presented in a stratum. The liquid crystal display screen is composed of six layers that work in combination to modulate light. ${ }^{4}$ Printers work with variable paper thicknesses that change the characteristics of printouts, and layers of ink are dropped, or electrically charged powder is fused to the face of the page. ${ }^{5}$ Images cannot be viewed without the depth constructions that render them visible. 

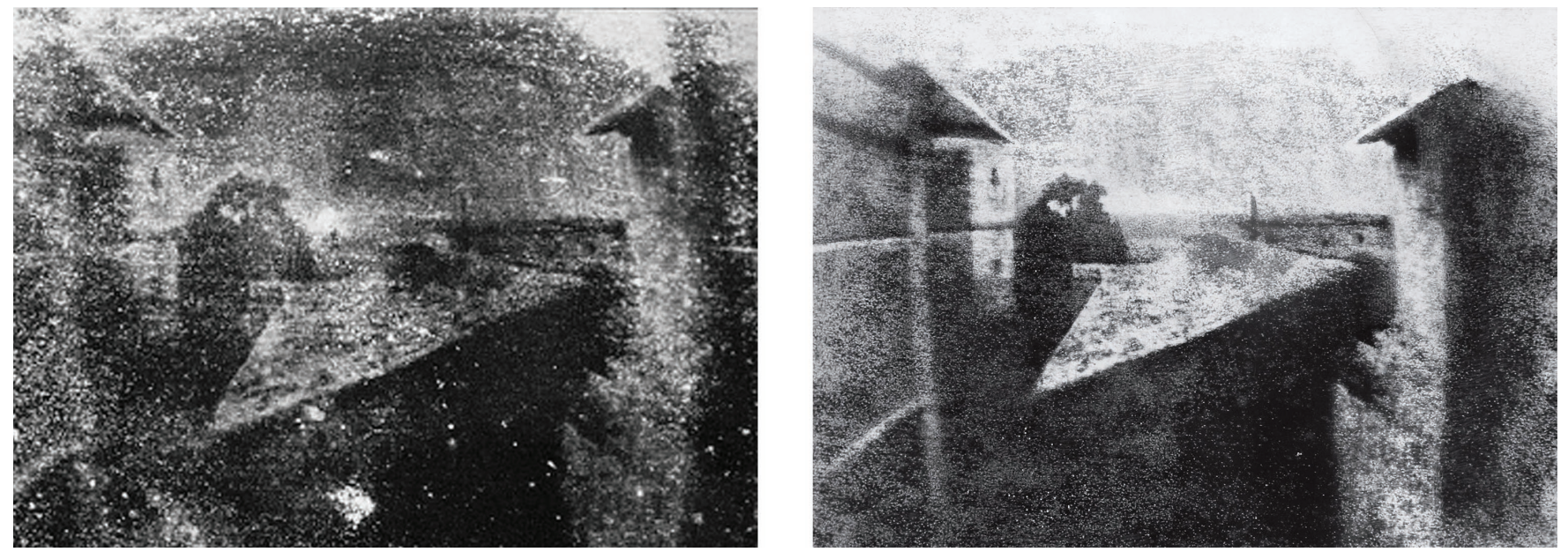

Figure 1. Nicéphore Niépce's 1827 heliograph, View from the Window at Le Gras. Kodak reproduction (left). Helmut Gernsheim's painting after a drawing as photographically reproduced (right). From Geoffrey Batchen, Burning with Desire: The Conception of Photography.

At once, images are data, ${ }^{6}$ and data exceeds the pictorial aspect of images and swallows everything in the magnitude of its wake. ${ }^{7}$ Data is always already plural, as it refers to a set of related figures that undergo multiple layers of translation when accessed. Computers translate matrixes of letters, to numbers, to zeros and ones, to electronic signals filtered through transistors. These signals control matrices of picture elements - or pixels - that alter the chrominance and luminance of a screen. As such they exploit human optical and cognitive abilities to interpret visual information when viewed at a distance. ${ }^{8}$ Through each conversion, data shifts its identity in order to present to its momentary humanoid or mechanical audience. These datasets that we might mistakenly conceive as immaterial are material in that they are processed energy. ${ }^{9}$ Images are inseparable from the layered processes at play in their storage; image data consumes power and occupies volumes, filling up hard drives and server rooms. Vast data sets of layered, non-linear accumulations have subsumed the singularity of any datum.

\section{PICTURING IMAGES}

With all this said, the term remains muddy. Unless fitted with a prefix - i.e., electronic, digital, or photographic - the word "image" slips between categories. The domain of images is further complicated in its definition, fragmenting from the visual, to the cognitive, and the technical. Concerning the visual, images are "likenesses," from the Greek eikōn, or icon; they are a sign or representation. The cognitive use of the term is bound up in imagination, wherein ideas can be described as "mental images." However, this categorical distinction is not clear as even the word "idea" is drawn from the Greek idein, to see. In the technical definition, variable apparatuses filter the defined information of images, from the camera's manipulation of light, to medical imaging devices's scanning of objects with electromagnetic beams, to the electronic signals of the computer as conveyed on a screen. ${ }^{10}$ None of these remain entirely discreet, and images straddle all three categories in varying degrees. An examination of images benefits from a widened scope of interrogation that acknowledges this inherent impurity of its denotation.

A case of the multivalence of images can be found in the history of photography. The widely recognized "first photographic image"11 is in itself a conflation of types. Geoffrey Batchen describes the unusual status of the heliograph famously captured by Nicéphore Niépce in his 1827, View from the Window at Le Gras (figure 1). The heliograph could not be photographically reproduced for publication, given the reflective properties of its pewter plate. ${ }^{12}$ In 1952, Kodak Research Lab was commissioned by the heliograph's owner, Helmut Gernsheim, to produce a reproduction. This reproduction was so unsatisfactory to Gernsheim, that he produced a drawing constructed from a close study of the plate, then spent two days retouching Kodak's copy by water-coloring dots over the photograph to convey his idealized reflections on its effects. ${ }^{13}$

Consequently, this historical photographic image is not so much a photograph as it is a reproduction of "a painting after a drawing. ${ }^{14}$ It is partially bound to the conventions of drawing, the optical play of a painting technique composed of scores of marks, and the material and technical characteristics of multiple photographic processes. This faux photograph manages to deceive its viewers into assuming a narrative of its singular construction. It is an image in all its impurity, masquerading as one thing but inscribed in the logic of others.

Rather than sequester digital imaging, contaminating the discrete worlds of multiple image types allows for their potential to be opened up across the visual, cognitive, and technical. This investigation intends to remain precise in these terms, combining image types not to dilute them, but to look for productive hybrids. As such, we can examine how physical artifacts confer the aesthetic effects of their material data onto the world of things that are under their spell. 

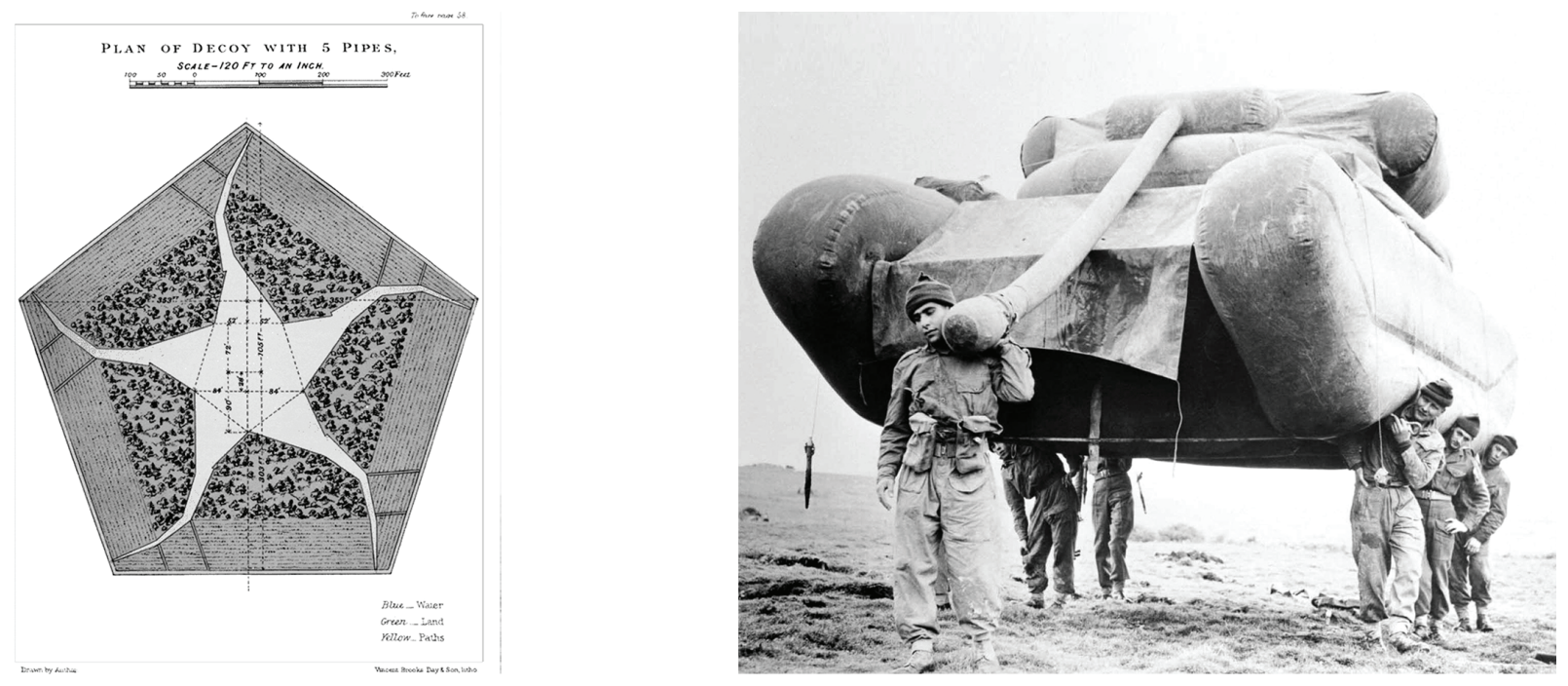

Figure 2. A plan of a decoy with five pipes from Sir Ralph Frankland-Payne-Gallwey, The Book of Duck Decoys, 1886 (left). Inflatable Tank from Rick Beyer, Elizabeth Sayles, The Ghost Army of World War I (right).

This examination raises a series of questions that interrogate the capacity of images to transform architecture through a dualistic analysis of data and picture. How might images impact the way that architecture is conceived and executed? Does the thickened flatness of images reshape how architects contend with translations between physical and virtual domains? What are the political boundaries suggested by images?

\section{A BRIEF HISTORY OF OBJECTS THAT WISH TO BE IMAGES} In order to examine contemporary architectural problems concerning images, it is helpful to look for clues amidst historical objects that become, or attempt to become images. Those analyzed here are bracketed in two categories: decoys and depictions. The contents of these categories are drawn not primarily from the discipline of architecture, but from theater, photography, and various practices that employ models or dioramas. Generally thought of as representations, doubles, or fakes, they occupy replica worlds that are made to deceive. However, it is not their illusion that is of interest; instead, it is their ability to negotiate between image and object via the specifics of their layered formats and materializations.

Decoys and depictions are also defined by the unconventional relationship they establish between the conventional elements of pictures: the frame and the screen. Like images, the term "picture" is promiscuous. The two words are deployed interchangeably in a multitude of contexts, but pictures can be distinguished through in their historical lineage. Sourced from the Latin pictūra, meaning painting, ${ }^{15}$ pictures have been given a particular status in their denotative field. The picture plane, the confluence of the parallel material screen and illusory frame in painting, walks the line between coextensive material data and optical logic. Problematically, in the case of perspective, the picture plane has been conceived as an objective window to the "real." 16 Decoys and depictions detach the frame from the screen, blurring the definition of the real and wrapping the material-data of images around objects. Dislocating the screen and the frame from one another opens architectural potential through their distinction, separation, and translation.

\section{PART I: DECOYS}

To consider how decoys can instruct the study of architectural images it is useful to revisit their historical evolution. Decoys resist categorization; the word can describe an interior, a model, or a set, and takes on the qualities of an image. Unlike the inconspicuous disguise of camouflage, decoys are intentionally visible deceptions. As traps or lures, they must be alluring to their unsuspecting victims. Ultimately, decoys are props that turn the world into a staged image by undermining and overturning material, scalar, and ontological expectations through the construction of their frames and screens.

The most familiar use of the word "decoy" refers to models of waterfowl capable through their realistic representation of luring unsuspecting birds within range of hunters. Nevadan tribes, around 800 A.D., created woven tule frames and covered these with a layer of bird feathers, screening the faux bird body beneath. ${ }^{17}$ In order to make more permanent decoys, European and early American hunters carved schematic wooden birds as "symbols which suggest a bird to its mates circling high overhead." ${ }^{18}$ These grew beyond the scope of a single model bird into elaborate scenes that included a variety of species, akin to the variety of diorama found in a natural history museum. Each evolution of these decoys was deliberately tuned to the optical capacity of ducks as they perceive in aerial view at a distance. 

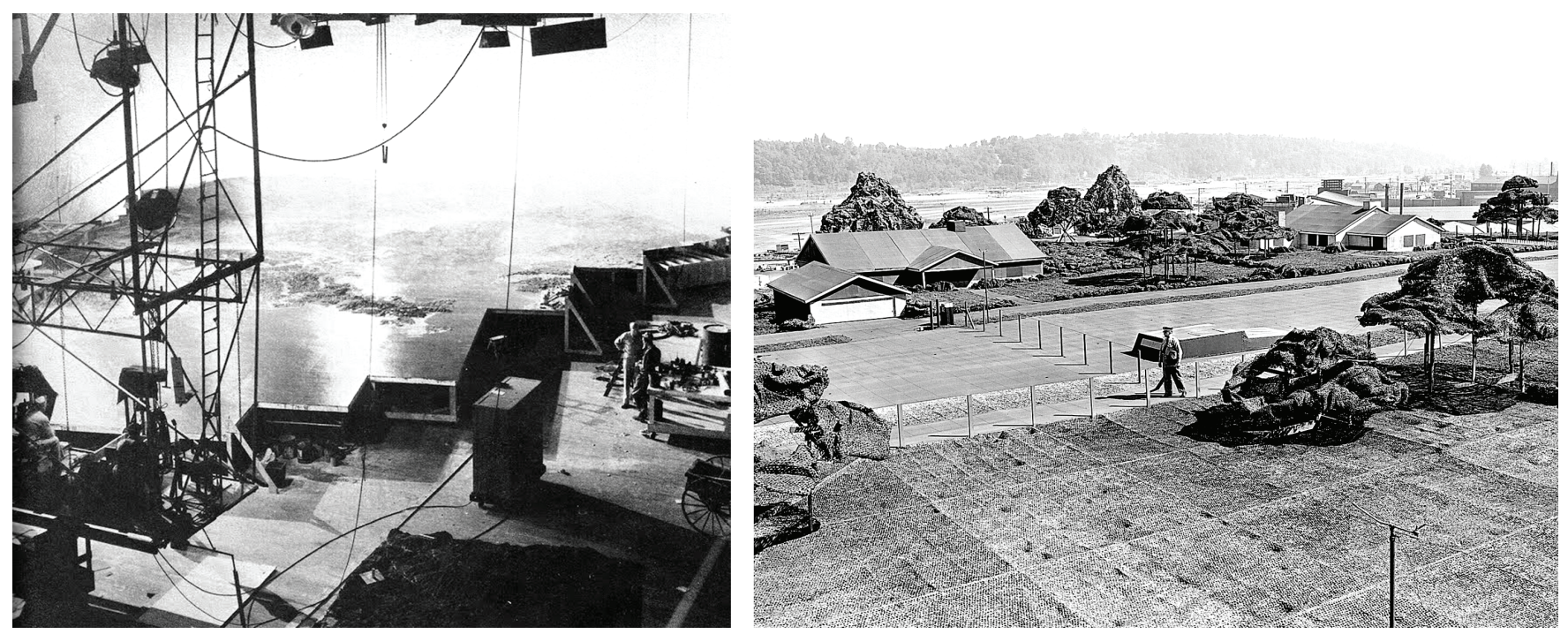

Figure 3. Norman Bel Geddes, Model of Tokyo Bay, from Michael S. Sherry, The Rise of American Air Power (New Haven and London: Yale University Press, 1989) (left). John Stewart Detlie for Boeing's “Wonderland" in Seattle, Washington, 1944, based on Colonel John F. Ohmer's camouflage developments for the US Military (right) (Boeing / Seattle Times archive).

These models of ducks were only later named decoys. The term was first implemented to describe the interiors of miniature architecture and intended to trap unwitting creature victims. Sourcing from the Dutch de kooi, meaning "cage," these labyrinthine tunnels consisted of watery paths surrounded by hoop frames, clad with a tunnel net that almost disappeared against the backdrop of the sky (figure 2). ${ }^{19}$ The paths were surrounded by an offset frame of wooden walls to obscure the hunters looming just outside, while live captives were used to lure wild ducks into the interior. ${ }^{20}$ Critical to this structure was the seamless continuity of the inner world to the world just outside the envelope. This staging required that the wooden enclosure was offset by some distance from the ducks' path of travel and precipitated the subtle narrowing of its curving streams beyond view. Defined by calculated manipulations, the bucolic interior deceives through its offset, invisible frame.

Decoys made a later appearance in military applications. During World War II, inflatable tanks, vehicles, and artillery were placed in key areas to fool enemies into believing forces were more vast than they were in actuality (figure 2). These artifacts of war bore more of a resemblance to theatrical props, created in large part by a fleet of artists and designers in the 23rd Headquarters Special Troops or "Ghost Army." ${ }^{21}$ The most significant parameters for these inflatables included size and weight for transportation and the time required for their inflation and deflation. These criteria controlled the object's construction in tandem with their desired effect. Faux military vehicles were composed of an inflatable rubber frame draped in a rubberized canvas screen, which required as little inflating air as possible to present the image of war. ${ }^{22}$ Unconvincing material orders could be identified up close, but were masked from a greater viewing distance; the puffed profiles of light-weight inflatables were set amidst tire tracks of the heavy vehicles to which they allude in order to create the illusion or their weight. ${ }^{23}$ Contemporary producers of inflatable military vehicles describe another significant factor in decoys: granularity, or the grain of detail inscribed in .2 $\mathrm{m}, .6 \mathrm{~m}$, or $6 \mathrm{~m}$ increments. ${ }^{24}$ The limits of the image, bound to the removed frame of aerial reconnaissance photography, control the necessary elaborations of the object's screen.

\section{PART II: DEPICTIONS}

Another branch of this investigation into objects that wish to be images includes what can be bracketed as depictions. Similar to decoys, depictions take multiple forms and may be a composite of a building, a room, a built-in, a model, or a painting. The latter plays a role in each example here described, framing depictions in the history of painted pictures. Again like decoys, they produce an object that capitalizes on our expectations of the world's continuity in order to play effectively against them. However, depictions must build the entire ground, staging a scene in order to frame their deceptions, rather than inserting a prop or exception into the existing surrounds.

L.J.M. Daguerre's diorama presents such a case of depiction. It displayed two large paintings, set 40 feet away from the audience, each at the end of an elongated hall. An operable viewing platform rotated the audience from one painting to the next, while concealed windows with mechanical shutters were used to direct light. ${ }^{25}$ The linen screens were painted on their front with standard illusionistic techniques, while the back side of the surface followed a different logic; painted shadows were rendered thick enough to be opaque, while 
points of light were left as blank linen. ${ }^{26}$ In the darkened interior, the screen was illuminated from the front to reflect light or from the back to refract or transmit. Working in tandem, the painted screen - subtly offsetting layers from both sides of the surface - and the framing building - the apparatus that extends far beyond the canvas - the frame and screen were separated and calibrated to control pictorial qualities, or "effects." 27 It is not the implied picture that creates the space of the diorama but by the apparatus-interior that it inhabits and the dimensional data of its material details.

Further cross-contamination of theater, cinema, and photography can be found in the "War Maneuver Models" of Norman Bel Geddes. Commissioned by Life magazine, these terrain models included powdered sugar or table salt waves and wakes, slanting threads of rain, cotton explosions and exhaust, and sterling silver vehicles made by jewelers. ${ }^{28}$ These materials were selected for their malleability, as the models were perpetual stop motion machines. That is, models were used to create near-cinematic sets of photos that were captured frame-by-frame, or they were updated over longer periods to reflect past scenes and speculate on future tactics. ${ }^{29}$ As such, the photographs record possible futures and history without distinction, dissolving any relationship to objective "facts." Built directly onto the floor or sometimes lifted on plywood scaffolding, ${ }^{30}$ the models reached up to 60 feet in size and covered as many as 150 square miles in scale. ${ }^{31} 32$ These models became large enough to create an alternative constructed ground. Surrounded by lights and other elements of soundstages, the models were staged in response to the photographic frame, at a remove from their structural frame (figure 3 ). The status of these images is particularly fraught in their relation to time as well as in their complex translation through building, model, photographic lens, and their reproduction in printed media.

Another such example shifting further into theater is Colonel John F. Ohmer's camouflage, developed with teams of Hollywood film-makers during World War II (figure 3). Ohmer concealed US military bases and aircraft plants behind a giant painted canvas screen that depicted faux suburban landscapes. ${ }^{33}$ These near theatrical sets were replete with four foot tall hollow wooden houses, chicken feather and spun glass landscaping, inflated rubber or plywood cars, and lumpy burlap trees propped on wood stud tree trunks. ${ }^{34}$ The uncanny domestic landscape acted an inaccessible "horizontal facade." 35 Its qualities were controlled for at an extreme remove; the characteristics of the flattened, low-resolution, large-scale model had been calibrated to the monofocal capacity of cameras used in military reconnaissance. ${ }^{36}$ The primacy of the camera as the image's audience led to the strangely proportioned vertical dimension, just tall enough to produce convincing shadows. The underlying frame and the canvas screen are doubled at an extreme remove, in the camera lens and printed photograph.

\section{BUILDING IMAGES}

All of these cases feature layered constructions and formats that detach frame from the screen. Pictorial ambitions are entangled with the dimensional specifics and material data as controlled through the space of production and display. These historical image types are ultimately transformed by translations that confer a multitude of image statuses onto them. In this way, each layer's constraints complicate the real through its depiction.

Returning to contemporary images in architecture, we find objects are structured by translation, not through drawing but through image. These objects accumulate the residue of the images through which they pass. Furthermore, architects are deploying images not only as a mode to show work but as a way to produce work through the feedback loop created as objects pass through images. Simultaneously, time is attenuating in the viscosity of electronic media. The slowness of the architecture is being confronted by the swiftness of posting. With this shift, architecture is becoming more like theater. Projects are presented to an unseen audience as a series of scenes. As such, the material properties of images, as well as the labor that is undertaken in their production and display, become inscribed in building.

\section{A CASE STUDY IN BUILDING IMAGES}

Engaging the potential of images requires looking for opportunities to build in ways that test the potential of thick material data. The design of a theater sets, like the one made for Insight Theatre Company's production of Silent Sky ${ }^{37}$ and a series of studies developed from that work have served as research into this potential (figure 4). The set and its offshoot studies are characterized by strange speciations of image mapped objects. These layered constructions are composed of digitally rendered images and physically modeled and photographed animations, projected onto a three-dimensional screen composed of cartesian and oblique surfaces. Constructed as a series of decoys - a digital model, a 1:8 scale model, a 1:1 scale model (the screen), and a digital projection mapping model - all elements are built with partial data that, when combined, produce a complete picture. Each model confronts a different methodology of image mapping and transposes its internal logic onto the others.

In the digital model, materials and features are applied through texture mapping, relating pixels to the UV axes of surfaces. Different components of the model are rendered as stills or animated and composited with the 1:8 scale model. 

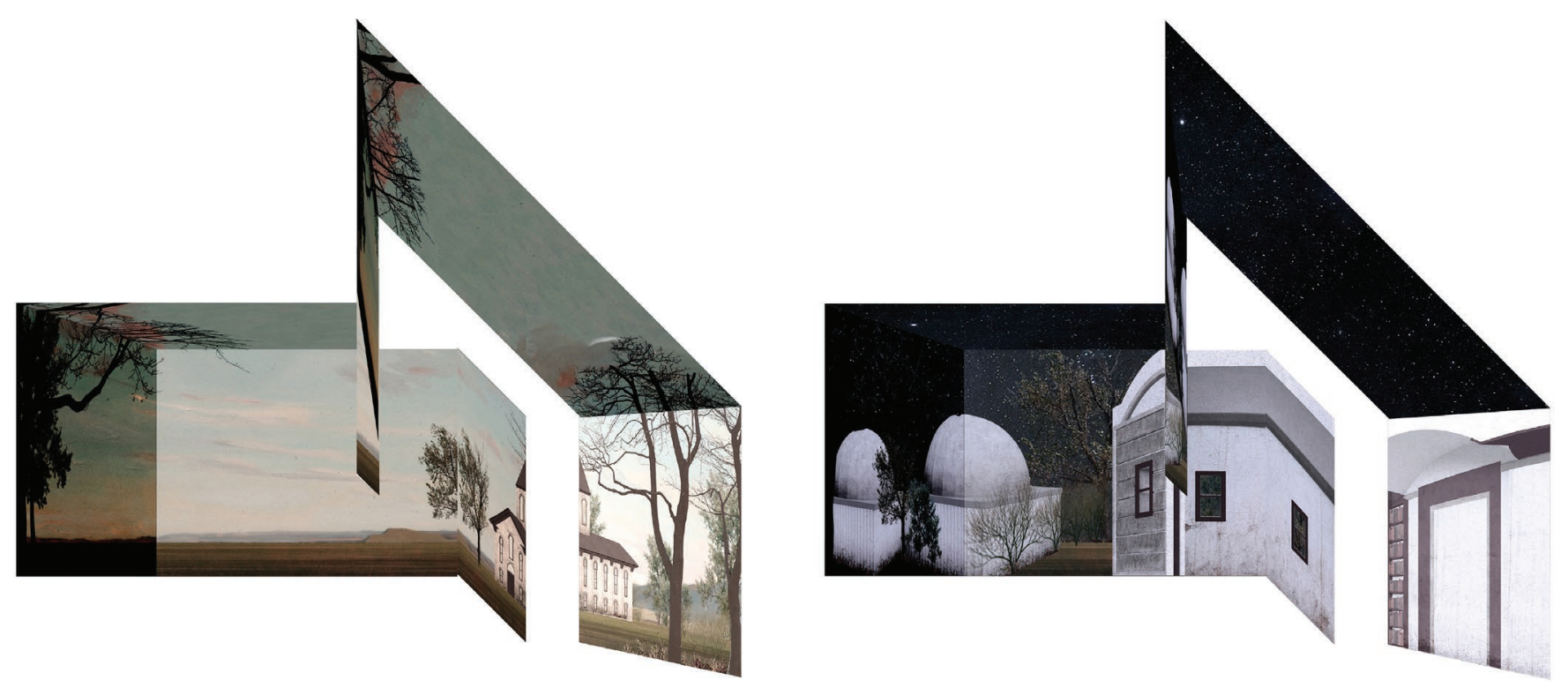

Figure 4. Theater set design studies for Insight Theatre Company's production of Silent Sky, 2018, courtesy of the author.

That $1: 8$ scale model is clad - physically mapped - in superficial material or printed images that are laden with material effects. It is then photographed in a series of stop motion frames and image-mapped back onto portions of the digital model or composited with renderings and projected on the 1:1 scale model. The 1:1 scale model inscribes a room that is offset from the surrounding one of the black box theater. The walls of the doubled interior are covered in white paint or fabric and receive a projected animation. This moving image is projection mapped, using software wherein the corners and edges of surfaces can be specified in order to distort and mask projected images onto the 1:1 model. In this projection mapping model, the Cartesian grid deforms to the surfaces of the 1:1 model and is tied into the coordinate location and orientation of the projector in the room.

Strange irregularities start to emerge in the mapping. Despite its strategies of depiction, it subtly reveals the logic with which it has interfaced and reveals the labor of its construction. Image mapping misregisters on the 1:1 model. Parts of the projection are mapped onto physically projecting, built elements of the three-dimensional screen, while others that are not built fall flat onto the backdrop. Some built elements remain on stage after their scene, although their image mapping is removing leaving only ghostly shadows of their previously mapped presence. Backlighting behind the screen shifts the image's visibility and allows the 1:1 model to project its construction in silhouette partially dissolving the image into colored light.

The enveloping projected image is distorted multiple times in order to map uniformly onto the oblique surfaces of the threedimensional screen. The multiple frames that underly these transformations - both unseen controlling and structural frames - show through in the oblique orientation of objects and textures. Objects depicted in the scene are rendered or built as worm's eye obliques, aligning the pictorial information to the geometry of the screen. Depicted corners coincide with the 1:1 model's corners. However, the corners of the screen surfaces do not meet. Instead, they exist in an unfolded state and displace the continuity of the projected image.

An automated track of atmospheric changes coincides with material shifts in the prop furniture to suffuse image with architecture. Projected image or video layers are scheduled in projection mapping software linked with audio and lighting. Simultaneous and staggered shifts between image, audio, and lighting indelibly tie the programmed data to the material of the room.

This project is an attempt to examine the possibilities in architecture of layered image formats, all of vastly different orders, and compressing them in an accumulative digitalmaterial image. Each translation acts as both polishing grit erasing some portion of the other and leaves the sticky residue of its properties. The projected doubles have no original, no singular vantage, nor do they require a linear reading of the image history. Nothing can be pointed to as the objective source as all elements contribute only a partial picture. There is no real at the center, only a series of fabricated reals.

\section{THE POLITICS OF IMAGES}

Looking through the lens of decoy and depictions presents new possibilities to define the architecture through layered images. Their displacing of the screen from the frame delaminates perceived frozen hierarchies. At once, labor is rendered visible as the image breaks down to partially reveal its 
construction. As with theater, there is an inherent collectivity to these images; multiple actors contribute to its effects, in the form of image data, interfaces, teams of designers. This collectivity extends to the reception of these images, made to be seen and awaiting a constant possible audience.

Operating with attention to the parameters of each image type opens questions across the visual, cognitive, and technical reach of images, from representation, to conceptualization, to information. If the audience reconfigures their vision to see that information forms complex histories and distorts as it changes formats or travels, might they also see that the world outside of the image in question is composite too? If so, perhaps images can reveal in part the complex relationships of that underline political issues. That nothing is exactly as it seems and that neither reality and nor its representations are a given.

Recognizing images as animated, delaminated, and material means seeing the world as having dynamic orders. In the pockets between the layers of images, the world is repictured as productively unstable. Images, seen in this light, complicate perception and make us see through other eyes. Images are visually comprehensible piles of information that speak to the complicated web of material information that they chart, geopolitical boundaries they cross, and energy they consume. In this way, we can see images as inherently political enterprises and read their capacity to engage in rewriting material, informational, and spatial boundaries.

\section{ENDNOTES}

1 Eve Blau and Edward Kaufman, Architecture and Its Image: Four Centuries of Architectural Representation, Works from the Collection of the Canadian Centre for Architecture (Montreal: Canadian Centre for Architecture, 1989), 9.

2 Robin Evans, "Translation from Drawing to Building," from Translation from Drawing to Building and Other Essays (London: Architectural Association Publications, 1997), 199. Evan's refers specifically to drawing and the transcription of its qualities onto building.

3 Hito Steyerl, "In Defense of the Poor Image" from The Wretched of the Screen (Berlin: Steinberg Press, 2012), 32.

4 James D. Foley, et al., Computer Graphics: Principles and Practice, second edition (Boston: Addison-Wesley, 1997), 161.

5 Richard Benson, The Printed Picture (New York: Museum of Modern Art, 2008), 270

6 John May, "Everything is Already an Image" Log 40 (Spring/Summer 2017): 12.

7 Steve F. Anderson, Technologies of Vision: The War Between Data and Images (Cambridge, MA: The MIT Press, 2017), 1.

8 Vlado Damjanovski, CCTV: From Light to Pixels, third edition (Waltham: Elsevier, Butterworth-Heinmann, 2014), 232.

9 Scott E. Umbaugh, Computer Imaging: Digital Image Analysis and Processing (Boca Raton, FL: Taylor \& Francis, 2005), 269.

10 Oxford English Dictionary, accessed October 2, 2018. http://www.oed.com/ viewdictionaryentry/Entry/91618.

11 Geoffrey Batchen, Burning with Desire: The Conception of Photography (Cambridge, MA: The MIT Press, 1999), 246. See Batchen's footnote 47 for an extended list of sources that Gernsheim's reproduction as the first photograph.

12 Batchen, 125.

13 Batchen, 127

14 Batchen, 127
15 Oxford English Dictionary, "Picture, n." entry, accessed January 4, 2019. http:// www.oed.com/viewdictionaryentry/Entry/143501.

16 Hito Steyerl, "In Free Fall: A Thought Experiment on Vertical Perspective" in The Wretched of the Screen (Berlin: Steinberg Press, 2012), 18.

17 Hillel Schwartz, The Culture of the Copy: Striking Likenesses, Unreasonable Facsimiles (New York: Zone Books, 2014), 178. Nevadan tribes around 800 A.D. created tule decoys and Champlain tribes around the 1600 s used buckskin.

18 Schwartz, 178

19 Sir Ralph Payne-Gallwey, The Book of Duck Decoys, Their Construction, Management, and History (London: J. Van Voorst, 1886), 17-18.

20 Payne-Gallwey, 17-18.

21 Payne-Gallwey, 10.

22 Rick Beyer and Elizabeth Sayles, The Ghost Army of World War II: How One TopSecret Unit Deceived the Enemy with Inflatable Tanks, Sound Effects, and Other Audacious Fakery (New York: Princeton Architectural Press, 2015), 42.

23 Beyer and Sayles, 42.

24 See "Inflatech Decoy," official website, accessed September 15, 2018. http:// www.inflatechdecoy.com/.

25 Helmut Gernsheim and Alison Gernsheim, L.J.M. Daguerre: The History of the Diorama and Daguerreotype, second revised edition (New York: Dover Publications Inc., 1968), 14, 20.

26 Bryimage, "Le Diorama de Daguerre: reconstitution sur maquette d'une séance du Diorama Théâtre,"YouTube, 5:00, February 21, 2012. https://www.youtube. com/watch?v=VoCZscSBeOE.

27 Geoffrey Batchen, Burning with Desire: The Conception of Photography (Cambridge, MA: The MIT Press, 1999), 125-127, 143.

28 Thomas Grischkowsky, "Photographs from MoMA's 1944 Norman Bel Geddes' War Maneuver Models Exhibition," in Behind the Scenes, Library and Archives, February 25, 2015. https://www.moma.org/explore/inside_out/2015/02/25/ found-photographs-from-momas-1944-norman-bel-geddes-war-maneuvermodels-exhibition/.

29 Grischkowsky, “Photographs from MoMA's 1944 Norman Bel Geddes' War Maneuver Models Exhibition."

30 Michael Sherry, The Rise of American Air Power: The Creation of Armageddon (New Haven, CT: Yale University Press, 1989). The scaffold frame shown in the figure is found not in Bel Geddes models, but in similar models made by the US Army Air Forces for military training videos.

31 Enrique Gualberto Ramirez, "Larger Scales of Norman Bel Geddes," in This is a456, August 24, 2010. http://www.aggregat456.com/2010/08/larger-scales-ofnorman-bel-geddes.html

32 John Forney Ruby, "Air Forces School Works Out Battle Tactics Here for Aerial Combat Zones," Orlando Morning Sentinel, May 12, 1943; Norman Bel Geddes Theater and Industrial Design Papers 1873-1964, Job 487, Box 34, Job Diary Meeting Minutes, Correspondence, February-December 1943, Harry Ransom Center for the Humanities, University of Texas at Austin.

33 Bill Yenne, Panic on the Pacific: How America Prepared for the West Coast Invasion (New York: Regenery, 2016). Ohmer's techniques were used at Lockheed in Burbank, North American Aviation in Inglewood, Northrop in Hawthorne, Consolidated Vultee in Downey, among others. They were later coopted and developed by architect H. Roy Kelley and landscape architect Edward Huntsman-Trout for Douglas Aircraft Company operated plants at Santa Monica, El Segundo, and Long Beach and by art director John Stewart Detlie for Boeing's "Wonderland" in Seattle.

34 Yenne, Panic on the Pacific.

35 Amy Campos "Territory and Inhabitation," in The Interior Architecture Theory Reader (London: Routledge, 2018), 75.

36 Yenne, Panic on the Pacific.

37 Silent Sky was written by Lauren Gunderson, directed by Maggie Ryan, and presented at Kranzberg Arts Center in October, 2018. The author, Constance Vale, was the set designer and her team included Yeonho Cho, Yunki Cheug, and Zhouxian Deng. The design was built by Ryan Wilson, Jessica Fleeman, and the author. 